\title{
Long Noncoding RNA BCYRN1 Promotes the Proliferation of Colorectal Cancer Cells via Up-Regulating NPR3 Expression
}

\author{
Lei Gu Liesheng Lu Donglei Zhou Zhongchen Liu
}

Department of General Surgery, Shanghai Tenth People's Hospital, School of Medicine, Tongji

University, Shanghai, China

\section{Key Words}

Colorectal cancer $(\mathrm{CRC}) \cdot$ Long noncoding RNAs (InCRNAs) $\bullet$ BCYRN1 • Proliferation • Apoptosis

\begin{abstract}
Background/Aims: Long noncoding RNAs (IncRNAs) constitute a large proportion of noncoding transcripts that have recently emerged as a new class of important regulators in cancers. LncRNA BCYRN1, also known as BC200, has a potential function in tumorigenesis. However, the clinical significance of BCYRN1 and its effect on colorectal cancer (CRC) progression remains unclear. Methods: Quantitative reverse transcriptase PCR (qRT-PCR) was performed to investigate the expression of BCYRN1 in CRC tissues and cell lines. The biological function of BCYRN1 was also investigated through knockdown and overexpression of BCYRN1 in vitro. Microarray bioinformatics analysis was performed to analyze the putative targets of BCYRN1. Results: The results showed that BCYRN1 expression was significantly upregulated in 96 CRC tumor tissues compared with para-carcinoma control tissues. Additionally, BCYRN1 overexpression was associated with larger tumor size and advanced pathological stages in CRC patients. In vitro BCYRN1 knockdown significantly inhibited the proliferation and apoptosis of CRC cells. Furthermore, NPR3 was identified to be a target of BCYRN1 and was downregulated by BCYRN1 knockdown. Conclusion: Together, we provide the first evidence that BCYRN1 plays an oncogenic role in CRC cells. BCYRN1 may be a promising prognostic biomarker and a potential therapeutic target for CRC.
\end{abstract}




\section{Cellular Physiology Cell Physiol Biochem 2018;48:2337-2349

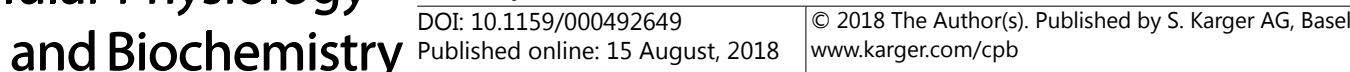

\section{Introduction}

Colorectal cancer (CRC) is known as the third most common cancer and the fourth cause of cancer death worldwide [1-3]. An estimated 600, 000 CRC deaths occurred each year in the world, and 376, 300 cases were diagnosed in China in 2015 [4, 5]. CRC has become a severe risk to human health for its poor prognosis [6, 7]. Understanding the genetic and molecular mechanism of CRC is critical for the development of an early diagnosis and an accurate therapy for CRC.

In recent years, mounting evidence has indicated that long non-coding RNAs (lncRNAs) have been participated in the development and progression of human diseases [8-10]. LncRNAs are evolutionarily conserved ncRNAs with more than 200 nucleotides in length and no protein-coding capacity $[11,12]$. Emerging evidence has shown that lncRNAs are implicated in multiple cellular biological processes, and several IncRNAs have been reported to be involved in CRC progression and tumorigenesis [13-16]. For example, IncRNA TUG1, one of the well-studied lncRNAs, is regarded as a critical diagnostic biomarker in CRC [17].

Dysregulation of IncRNA BCYRN1 has been found in various cancers, as well as in neurodegenerative diseases $[18,19]$. However, the clinical role of BCYRN1 and its biological functions in CRC remains unknown. Natriuretic peptide receptor C (NPR3) is an atrial natriuretic peptide receptor, which inhibits adenylyl cyclase activity via a Gi-coupled signaling pathway. In this study, we investigated the expression and biological function of BCYRN1 in CRC. Also, we defined the clinical role of BCYRN1 in CRC.

\section{Materials and Methods}

\section{Patients and tumor samples}

CRC tumor specimens and the adjacent normal tissues were collected from 96 patients underwent resection at the Shanghai Tenth People's Hospital, Tongji University between July 2010 and December 2013. Surgically resected tissues samples were immediately frozen in RNALater (Qiagen, Hilden, Germany) and subsequently stored at $-80^{\circ} \mathrm{C}$ until use. The clinicopathological data for histological grading, TNM staging, and lymph node status of CRC were histopathologically confirmed. The clinicopathological parameters of the CRC patients are summarized in Table 1. The study was approved by the Clinical Research and Ethics Committee at Shanghai Tenth People's Hospital, Tongji University. Written informed consents were obtained from all participants.
Table 1. Correlation between BCTRN1 and clinicopathological characteristics in 96 CRC patients. ${ }^{*}$ Chi-squared test. ${ }^{*} \mathrm{P}<0.05$

\begin{tabular}{|c|c|c|c|c|}
\hline \multirow{2}{*}{ Parameters } & \multicolumn{3}{|c|}{ BCTRN1 } & \multirow{2}{*}{$\mathrm{P}$} \\
\hline & & High & Low & \\
\hline Age (years) & & & & 0.583 \\
\hline$>50$ & 60 & 39 & 21 & \\
\hline$\leq 50$ & 36 & 24 & 12 & \\
\hline Sex & & & & 0.744 \\
\hline Male & 61 & 47 & 14 & \\
\hline Female & 35 & 25 & 10 & \\
\hline Tumor diameter $(\mathrm{cm})$ & & & & $0.043^{*}$ \\
\hline$\geq 5 \mathrm{~cm}$ & 34 & 22 & 12 & \\
\hline$<5 \mathrm{~cm}$ & 62 & 51 & 11 & \\
\hline Location & & & & 0.305 \\
\hline Colon & 37 & 26 & 11 & \\
\hline Rectum & 59 & 44 & 15 & \\
\hline TNM stage & & & & $0.017^{*}$ \\
\hline I & 4 & 4 & 0 & \\
\hline II & 19 & 10 & 9 & \\
\hline III & 27 & 24 & 3 & \\
\hline IV & 46 & 35 & 11 & \\
\hline Lymphatic metastasis & & & & 0.631 \\
\hline Yes & 44 & 33 & 11 & \\
\hline No & 52 & 40 & 12 & \\
\hline Distant metastasis & & & & 0.528 \\
\hline Yes & 12 & 9 & 3 & \\
\hline No & 84 & 63 & 21 & \\
\hline Tumor differentiation & & & & 0.096 \\
\hline Low & 25 & 18 & 7 & \\
\hline Middle & 67 & 52 & 12 & \\
\hline High & 4 & 3 & 1 & \\
\hline
\end{tabular}




\section{Cellular Physiology Cell Physiol Biochem 2018;48:2337-2349 \begin{tabular}{l|l|l} 
DOI: 10.1159/000492649 & $\begin{array}{l}\text { O } 2018 \text { The Author(s). Published by S. Karger AG, Basel } \\
\text { www.karger.com/cpb }\end{array}$
\end{tabular} \\ Gu et al.: The Oncogenic Role of BCYRN1 in CRC}

Table 2. Sequence of primer and siRNA

\begin{tabular}{|c|c|c|c|}
\hline Gene & Sense(/Antisense) & $\mathrm{Tm}$ & Length \\
\hline \multirow{2}{*}{ GAPDH } & $\begin{array}{l}\text { GTGACGTTGACATCCGTAAAGA } \\
\end{array}$ & 61.6 & \multirow{2}{*}{450} \\
\hline & GCCGGACTCATCGTACTCC & 60.3 & \\
\hline \multirow[t]{2}{*}{ Cabyr } & AGAGGATCACCTTGGGGTACA & 61.7 & \multirow{2}{*}{98} \\
\hline & CGAAGCGACAGATGGTGGTC & 62.9 & \\
\hline \multirow{2}{*}{ Pcsk4 } & TTGCTTACAAGGGTCTGCTACT & 60.4 & \multirow{2}{*}{106} \\
\hline & ACTGGTAGAAGAATCAGGGCT & 60.1 & \\
\hline \multirow{2}{*}{ My12 } & CCCTGAAGTCGAGGAGCTG & 60.9 & \multirow{2}{*}{114} \\
\hline & CTGCTGCACCTCTAAGCGA & 61.7 & \\
\hline \multirow{2}{*}{ Kng2 } & GAAGCGTCTCACTCCCGAAG & 62.3 & \multirow{2}{*}{93} \\
\hline & GAAGAAAACGTCGCGCTACT & 60.7 & \\
\hline \multirow{2}{*}{$\mathrm{Pla} 2 \mathrm{~g} 4 \mathrm{~b}$} & AGAGGATCACCTTGGGGTACA & 61.7 & \multirow{2}{*}{98} \\
\hline & CGAAGCGACAGATGGTGGTC & 62.9 & \\
\hline \multirow{2}{*}{$\mathrm{Cpz}$} & CAAACCTCAATGTGTCTCTTTGC & 60.2 & \multirow{2}{*}{97} \\
\hline & AGAGTAAAGCCTATCTCGCTGT & 60.4 & \\
\hline \multirow{2}{*}{ Npr3 } & СТTСССТСАTССTCСTGCTAC & 61.1 & \multirow{2}{*}{145} \\
\hline & ACAAACTGGGTAAAGGTGATGG & 60.2 & \\
\hline \multirow{2}{*}{ Rap1a } & CCAAAGCGGAGTCTCGCAT & 62.4 & \multirow{2}{*}{125} \\
\hline & GCCTAGCATCTTGCTTAGCTC & 60.6 & \\
\hline \multirow{2}{*}{ Dhrs9 } & TTGCTCCGGTAACAGCAGTG & 62.4 & \multirow{2}{*}{105} \\
\hline & GTGGTCGCTTGTGTAGAAGGA & 61.7 & \\
\hline \multirow{2}{*}{ Pdgfb } & ATGCTGGGAAAGTCATGGAAG & 60.0 & \multirow{2}{*}{201} \\
\hline & CGTGTTCTGGTCACGAGAGA & 61.2 & \\
\hline \multirow{2}{*}{ BCYRN1 } & TAAGCTTGTAACCTGCACCCGATTCACAG & 62.0 & \multirow{2}{*}{112} \\
\hline & TGGCAGCATACTCCTGACCATACTACCCG & 62.8 & \\
\hline si-BCYR1 & TCTGATCCGCTGTACTCTCCT & 60.3 & 60 \\
\hline si-Npr3 & GAGAATTTCAAGTCGTGGCGA & 61.2 & 63 \\
\hline
\end{tabular}

\section{Cell lines and cell culture}

Human CRC cell lines GEO, SW480, and LOVO and a normal human colon mucosal epithelial cell line NCM460 were all purchased from Shanghai Institute of Biochemistry and Cell Biology (Shanghai, China). SW480 and LOVO cells were cultured in Leibovitz's L-15 medium (L-15; Gibco) in a humidified chamber with 5\% CO2 at $37^{\circ} \mathrm{C}$. NCM460 and GEO cells were maintained in Dulbecco's modified Eagle's medium (DMEM; Invitrogen) under the same conditions. All the media were containing $10 \%$ fetal bovine serum (FBS; Invitrogen) and $100 \mathrm{U} / \mathrm{mL}$ penicillin and $100 \mathrm{mg} / \mathrm{mL}$ streptomycin (Invitrogen, Shanghai, China).

\section{qRT-PCR}

Total RNA was isolated from cultured cells and patient tissues using TRIzol (Invitrogen) according to the manufacturer's instructions. Total RNA was reverse-transcribed into complementary DNA (cDNA) using a PrimeScript RT reagent kit (TaKaRa Bio Inc., Japan), and qPCR was performed using SYBR Select Master Mix (Takara, Japan) on an ABI 7900 system (Applied Biosystems, USA). The reaction conditions were as follows: $95^{\circ} \mathrm{C}$ for $1 \mathrm{~min}$, followed by 40 cycles of $95^{\circ} \mathrm{C}$ for $15 \mathrm{sec}$ and $60^{\circ} \mathrm{C}$ for $1 \mathrm{~min}$. Expression levels were normalized to GAPDH, and were calculated using the comparative delta-delta CT (2- $\Delta \Delta \mathrm{Ct})$ method. All reactions were performed in triplicates. The primer sequences are shown in Table 2.

\section{Western blot analysis}

Total protein was isolated from cells, and protein concentration was detected using a bicinchoninic acid assay (BCA) kit (Thermo Scientific, MA, USA). The protein was subjected to SDS/PAGE and transferred to a polyvinylidene difluoride membrane (Millipore, Billerica, MA, USA). After blocking with 5\% nonfat milk powder in TBS-T buffer for 1 hour at room temperature (RT), the membrane was incubated with primary antibody against the target proteins overnight at $4^{\circ} \mathrm{C}$, followed by incubation with appropriate HRP-conjugated secondary antibodies. The protein bands were developed with the ECL System (Millipore, Billerica, MA, USA). The assay was performed three times. Anti- $\beta$-actin (Sigma-Aldrich, USA) was used for 


\section{Cellular Physiology Cell Physiol Biochem 2018;48:2337-2349 \begin{tabular}{l|l|l} 
and Biochemistry Published online: 15 August, 2018 & $\begin{array}{l}\text { @ } 2018 \text { The Author(s). Published by S. Karger AG, Basel } \\
\text { www.karger.com/cpb }\end{array}$ \\
\hline
\end{tabular}}

Gu et al.: The Oncogenic Role of BCYRN1 in CRC

an internal control. Anti-cyclinD1, anti-bcl-2, and anti-bax antibodies were purchased from Cell Signaling Technology, and anti-NPR3 antibody was acquired from Abcam.

\section{Cell transfection}

siRNA or DNA transfection was performed using lipofectamine 2000 reagent (Invitrogen, USA) according to the manufacturer's instructions. Sequences of si-RNAs (Carlsbad, California, USA) are shown in Table 1. For transient transfection, CRC cells were plated into six-well plates and transfected with BCYRN1siRNA, NC-siRNA, pcDNA-BCYRN1, pcDNA-NPR3 or empty pcDNA vector. The expression levels of BCYRN1 and NPR3 were detected by qRT-PCR.

\section{MTT assay and colony formation assay}

Cell proliferation ability was evaluated by MTT (Roche Applied Science, Switzerland) assay at $48 \mathrm{~h}$ post transfection [20]. Transfected cells were seeded into 96-well plates at a density of $3 \times 10^{3} /$ well and routinely cultured for $6 \mathrm{~h}, 24 \mathrm{~h}, 48 \mathrm{~h}, 72 \mathrm{~h}$ and $96 \mathrm{~h}$, respectively. Colony formation was conducted according to previously published procedures [20]. The rate of colony formation was determined using the following formula: colony formation rate $=$ (number of cells/primary number of cells) $* 100 \%$

Cell cycle and apoptosis analysis

Cell cycle and apoptosis analysis were performed as described previously [20]. Double staining with annexin V and PI for apoptosis detection and single staining with PI for cell cycle analysis were conducted at $48 \mathrm{~h}$ post transfection. The measurements were performed in triplicate.

\section{EdU immunoflurescence assay}

At $48 \mathrm{~h}$ post transfection, cell proliferation was determined using 5-ethynyl-2'-deoxyuridine (EdU) immunoflurescence assay according to the manufacturer's instructions (Ribobio, Guangzhou, China). Briefly, CRC cells were seeded into 96-well plates at a density of $5 \times 10^{3} /$ well and routinely cultured. After transfection for $48 \mathrm{~h}$, the culture medium was replaced with new medium containing $50 \mu \mathrm{M}$ EdU. With another $2 \mathrm{~h}$ incubation, cells were fixed with formaldehyde (4\%, $\mathrm{pH}=7.4)$ for $30 \mathrm{~min}$. After treating with $0.5 \%$ Triton X-100 for $20 \mathrm{~min}$, cells were washed with PBS and counterstained with anti-EdU reagents for $30 \mathrm{~min}$. Subsequently, after a $30 \mathrm{~min}$ incubation with $100 \mu \mathrm{L}$ Hoechst $33342(5 \mu \mathrm{g} / \mathrm{mL})$ at RT, cells were visualized by fluorescence microscopy. The level of cell proliferation was determined using the following formula: cell proliferation $=($ number of EdU-positive cells/all cells $) * 100 \%$.

\section{TUNEL apoptosis assay}

Apoptosis was detected using a terminal deoxynu-cleotidyl transferase dUTP nick end labeling (TUNEL) apoptosis assay kit (KeyGEN BioTECH, Nanjing, China). Cells were defined as apoptotic if the entire nuclear area of the cell was positively labeled. Apoptotic cells and bodies were counted in ten highpower fields. The apoptotic index (AI) was calculated as the percentage of positively stained cells using the following equation: $\mathrm{AI}=$ number of apoptotic cells/total number of nucleated cells.

\section{Microarray expression analysis}

cDNA preparation, hybridization, and data analysis were carried out using Affymetrix TM HG-U133 Plus 2.0 ( Affymetrix, Santa Clara, USA) following the manufacturer's instructions. Microarray slides were scanned and pre-analyzed using GeneSpring GX (Agilent Technologies, Inc., Santa Clara, USA), followed by further normalization using Robust Multi-array Average (RMA). Then, the summarization algorithm conducts background correction. Quality control check on all samples was carried out using the principal component analysis (PCA), and correlation coefficients of each pair of arrays were displayed in visual form as a heatmap. A two-fold change in expression and a p-value $<0.05$ were recognized as significantly differentially expressed genes. 


\section{Cellular Physiology Cell Physiol Biochem 2018;48:2337-2349 \begin{tabular}{ll|l} 
and Biochemistry Published online: 15 August, 2018 & $\begin{array}{l}\text { (c) } 2018 \text { The Author(s). Published by S. Karger AG, Basel } \\
\text { www.karger.com/cpb }\end{array}$ \\
\hline
\end{tabular}}

\section{Statistical analysis}

All data were presented as the mean \pm standard error (S.E.M.) from at least three independent experiments. Statistical significance was assessed by two-tailed Student's $t$-test or one-way multivariate analysis of variance (ANOVA) using SPSS 19.0 statistical software (SPSS, Inc., Chicago, IL, USA). A $P$ value less than 0.05 was considered statistically significant.

\section{Results}

\section{BCYRN1 expression in CRC tissues and cell lines}

We examined the expression levels of BCYRN1 in 96 CRC tissues and 96 paired adjacent normal tissues by qRT-PCR. As shown in Fig. 1A, BCYRN1 expression was significantly higher in CRC tissues than that in adjacent normal tissues $(P=0.003)$. Then, we evaluated the correlation between BCYRN1 expression and clinicopathological characteristics. As shown in Fig. 1B and C, BCYRN1 expression was associated with the tumor stage $(P=0.017)$ and the tumor size $(P=0.043)$. To explore the biological functions of BCYRN1 in CRC progression, we knocked down BCYRN1 expression in SW480 and LOVO cells by transfection of si-BCYRN1 and enhanced BCYRN1 expression in GEO cells by transfection of pcDNA3.1-BCYRN1. BCYRN1 knockdown and ectopic expression in CRC cells were confirmed by qRT-PCR $(P<0.01$, Fig. 1D).

\section{$B C Y R N 1$ promotes $C R C$ cell proliferation}

MTT assay results showed that BCYRN1 knockdown remarkably inhibited cell proliferation in SW480 and LOVO cells compared with control transfected cells, whereas overexpression of BCYRN1 markedly increased cell proliferation in GEO cells compared with cells transfected with vector (Fig. 2A). The clonogenic ability of CRC cells was accessed using the colony formation assay. As shown in Fig. 2B, knockdown of BCYRN1 significantly inhibited the colony formation in SW480 and LOVO cells compared with control transfected cells $(P<0.05)$, whereas overexpression of BCYRN1 markedly increased the colony formation in GEO cells $(P<0.05)$. These results were also confirmed by EdU/Hoechst immunostaining assay (Fig. 2C). Together, these results suggested that BCYRN1 is involved in CRC cell proliferation.

Downregulation of BCYRN1 induces G1 phase arrest and promotes apoptosis in CRC cells

To explore the potential mechanism of BCYRN1 in CRC cell proliferation, apoptosis analysis was performed using flow cytometry. The results showed that knockdown of BCYRN1 induced cell cycle arrest at G0/G1 phase $(P<0.05$, Fig. 3A). Consistently, the expression of cyclin D1 was decreased in si-BCYRN1 transfected cells compared with control cells (Fig. 3A). Moreover, we found that BCYRN1 knockdown remarkably promoted apoptosis in SW480 and
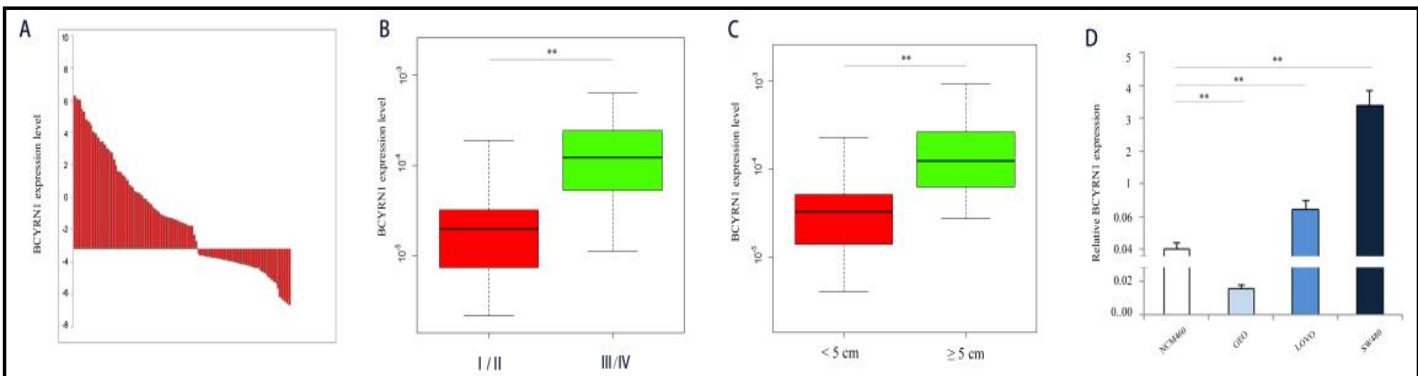

Fig. 1. Expression levels of BCYRN1 in tissues and cells. A: qRT-PCR was performed to determine the expression levels of BCYRN1 in 96 CRC tissues and 96 adjacent normal tissues. GAPDH was used as the endogenous control. B: The expression levels of BCYRN1 in tumor tissues with different pathological stage. C: The expression levels of BCYRN1 with different tumor size. D: The expression levels of BCYRN1 in different CRC cell lines compared with normal cell line. ${ }^{*} \mathrm{P}<0.05,{ }^{* *} \mathrm{P}<0.01$. 


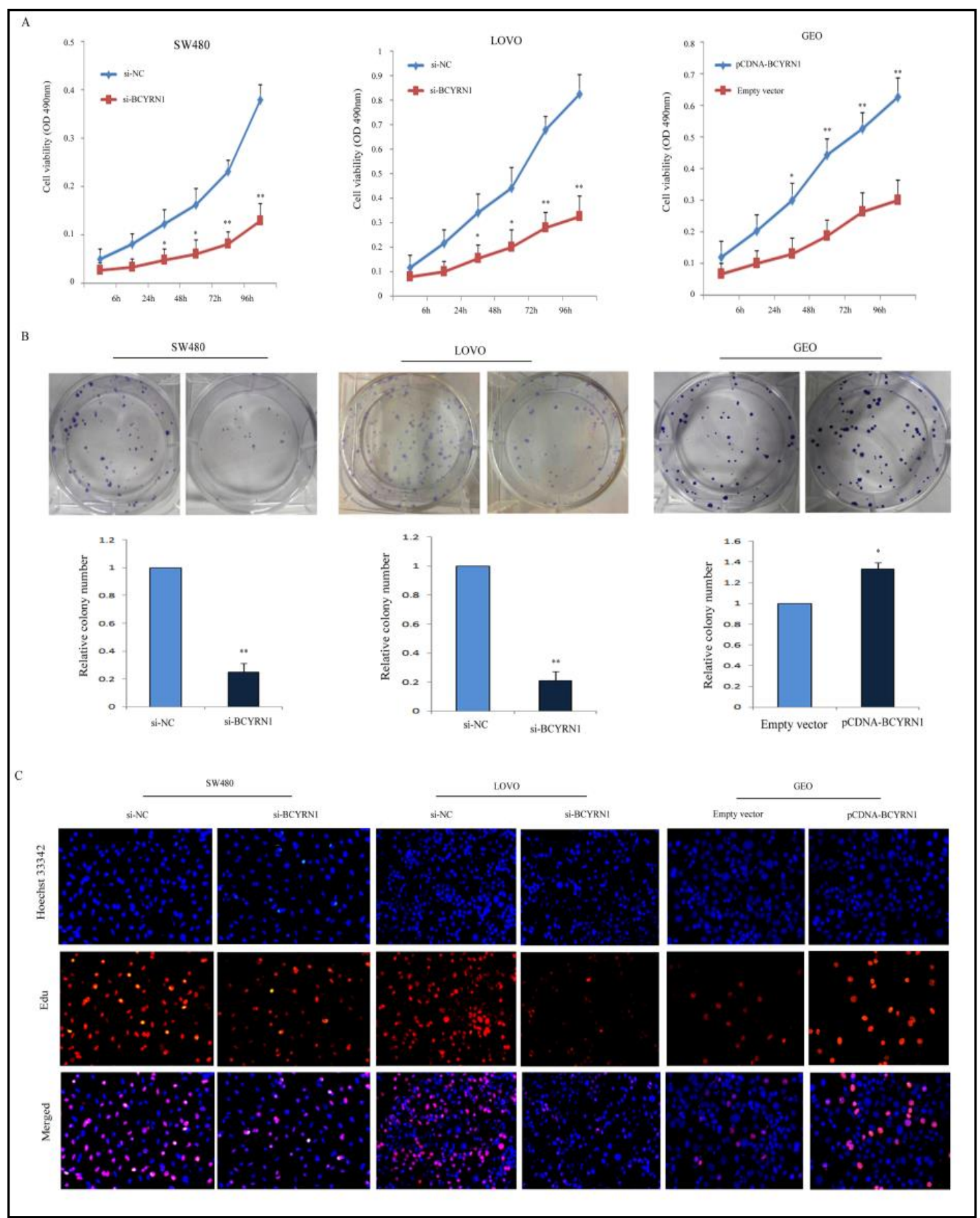

Fig. 2. Effects of BCYRN1 on CRC cell proliferation. (A) MTT assay, (B) colony formation, and (C) EdU immunoflurescence assay were performed to determine the proliferative ability in SW480, LOVO and GEO cell lines. ${ }^{*} \mathrm{P}<0.05,{ }^{* *} \mathrm{P}<0.01$. All data were presented as the mean \pm S.E.M. from at least 3 independent experiments.

LOVO cells $(P<0.05$, Fig. 3B). Results from TUNEL assay also indicated that the number of TUNEL positively stained cells increased in BCYRN1 knockdown cells (Fig. 3C). In addition, Bax expression was markedly upregulated while Bcl-2 expression was downregulated in cells treated with si-BCYRN1 (Fig. 3D). These results suggested that BCYRN1 contributes to the apoptosis of CRC cells.

\section{KARGER}




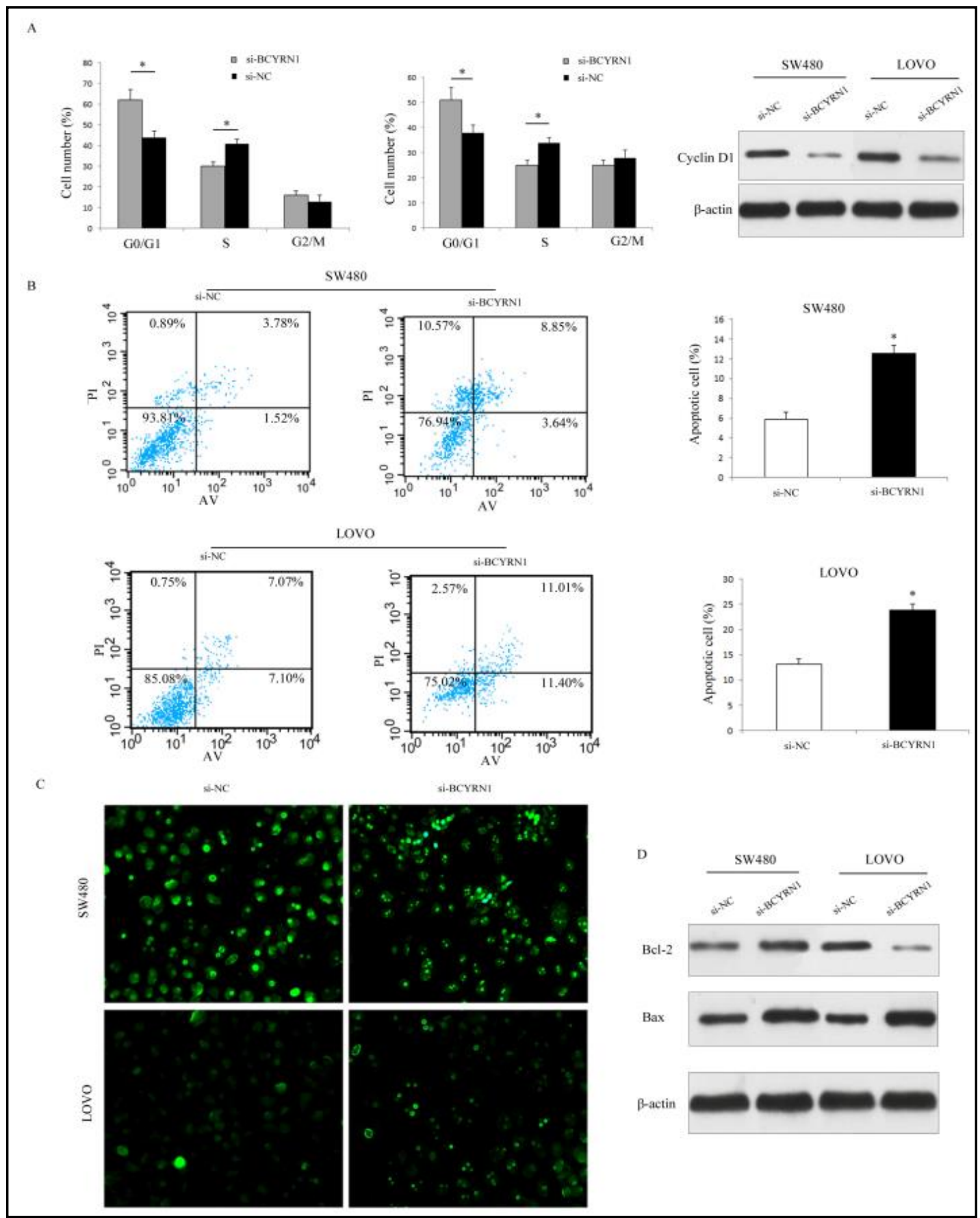

Fig. 3. Effects of BCYRN1 on cell cycle and apoptosis of CRC cells. (A) The percentage of cells in G0/G1 phase, $\mathrm{S}$ phase and G2/M phase was presented in the histogram (left panel). Western blotting was carried out to detect cyclin expression in SW480 and LOVO cell lines (right panel). (B) Cell apoptosis was analyzed using flow cytometry and (C) fluorescence microscopy. (D) Western blotting was carried out to determine Bax and Bcl-2 expressions in SW480 and LOVO cell lines. ${ }^{*} \mathrm{P}<0.05$. All data were presented as the mean \pm S.E.M. from at least 3 independent experiments. 


\section{Gene expression profiles}

To identify BCYRN1 knockdown-mediated transcriptional changes, we used microarray analysis to compare the expression profiles between cases and controls. The threshold used to screen up- or down-regulated genes was Fold Change $>=2.0$ and p-value $<=0.05$ (Fig. 4A). The significantly differential expression genes were identified compared with control group. To confirm the microarray data, the top five up or down regulated genes were determined

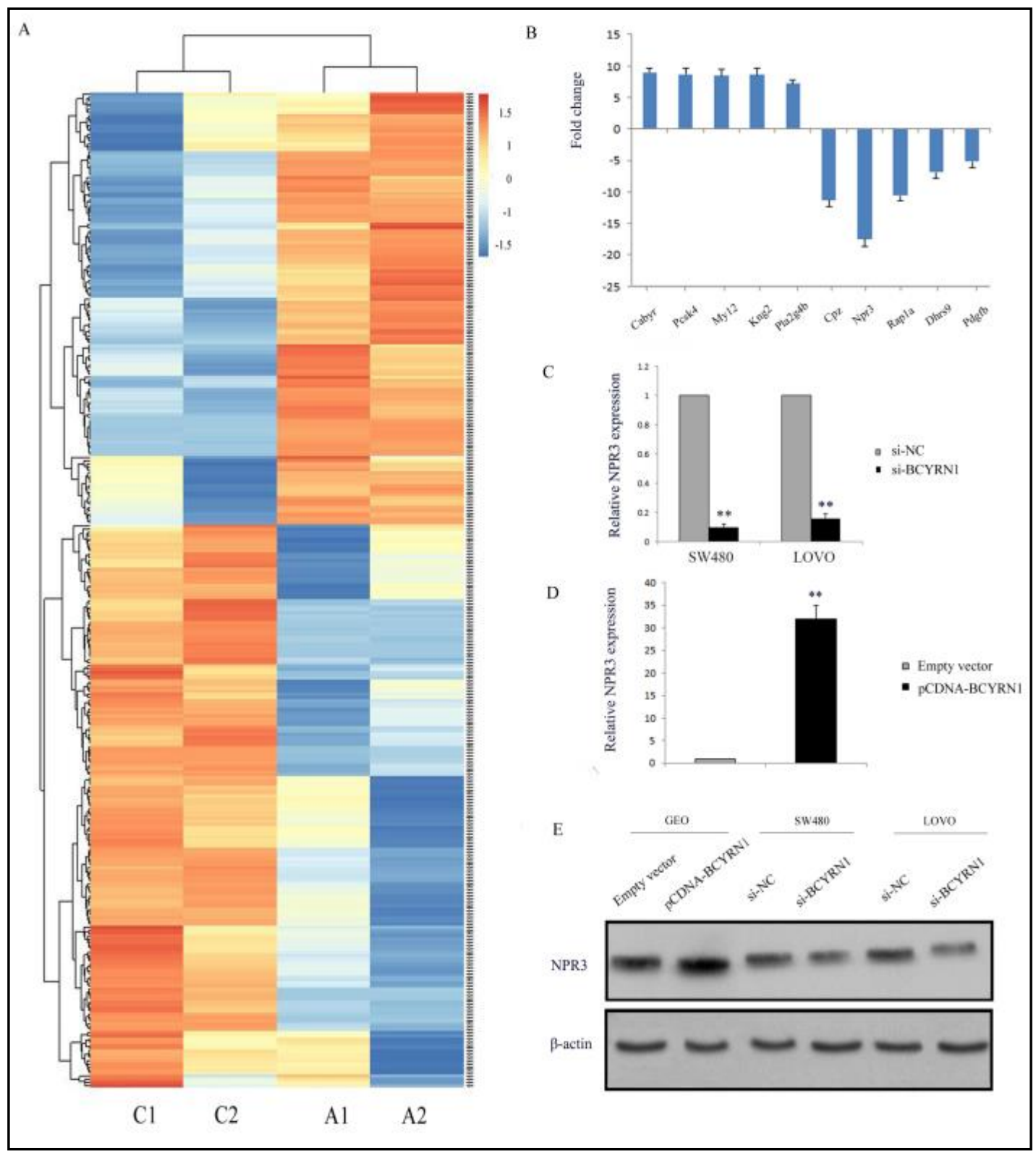

Fig. 4. Microarray expression analysis of SW480 cells with BCYRN1 knockdown. (A) Upregulated genes (orange) and downregulated genes (blue) with significantly differential expression ( $\geq 2.0$-fold) were identified compared with control group. (B) qRT-PCR was performed to determine the top five up- or downregulated genes with significantly differential expression. GAPDH was used as the endogenous control. (C) qRT-PCR was carried out to detect NPR3 expressions in SW480 and LOVO cell lines treated with control siRNA (si-NC) or si-BCYRN1. (D) qRT-PCR was carried out to detect NPR3 expressions in GEO transfected with vector or pcDNA-BCYRN1. (E) Western blotting was performed to detect NPR3 expressions in SW480, LOVO and GEO cell lines after BCYRN1 knockdown or overexpression. ${ }^{*} \mathrm{P}<0.05$, ${ }^{* *} \mathrm{P}<0.01$. All data were presented as the mean \pm S.E.M. from at least 3 independent experiments. 
using qRT-PCR (Fig. 4B). Next, we focused on NRP3, whose expression was mostly changed upon BCYRN1 alteration. We found that knockdown of BCYRN1 significantly decrease NPR3 mRNA and protein expression, whereas overexpression of BCYRN1 markedly upregulated NPR3 mRNA and protein expression (Fig. 4C-E). These results suggested that BCYRN1 could regulate NPR3 expression.

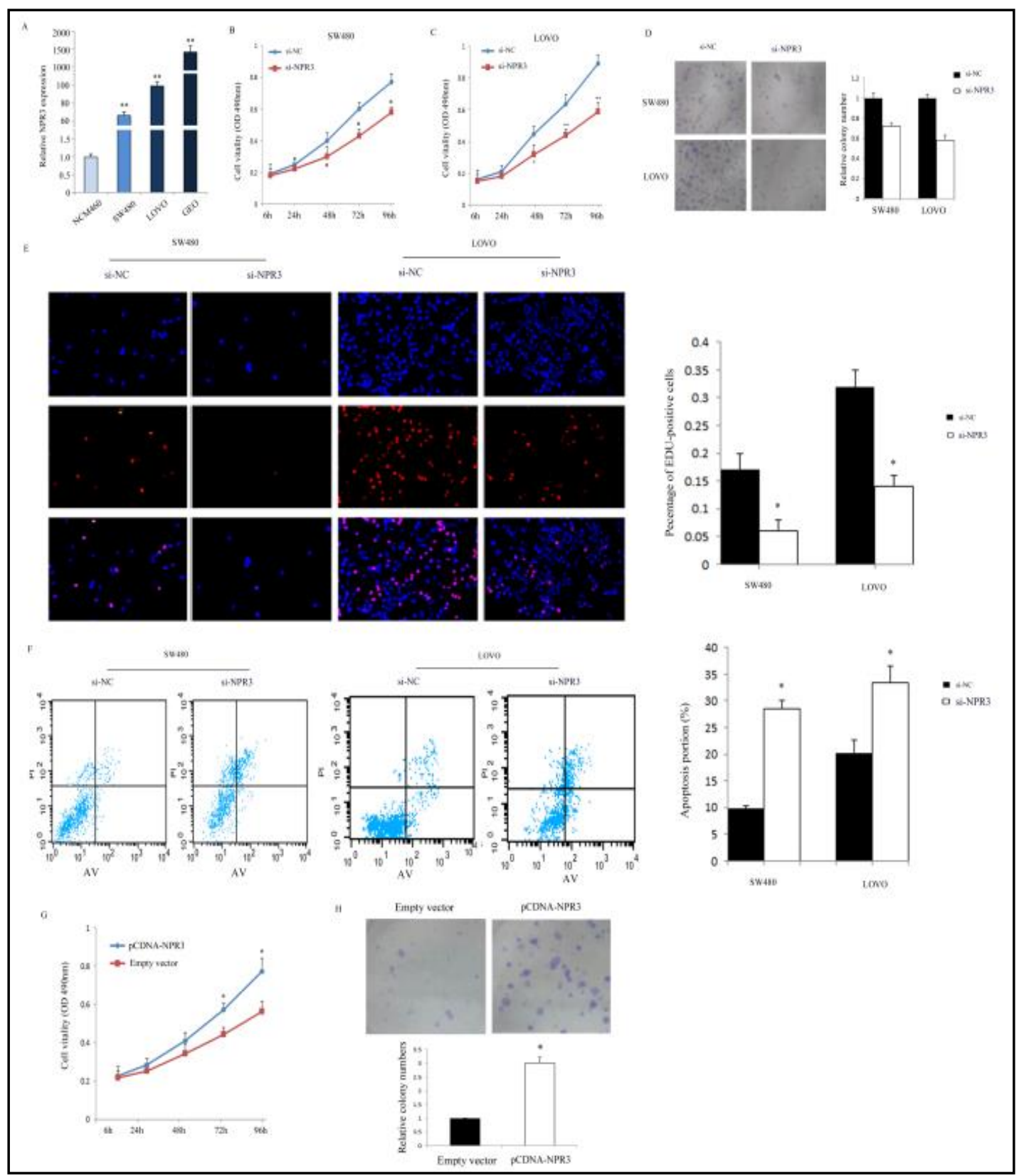

Fig. 5. Effects of BCYRN1 on the proliferation and apoptosis of CRC cells. (A) qRT-PCR was performed to determine NPR3 expressions in SW480, LOVO, GEO, and NCM460 cell lines. (B, C) MTT assay, (D) colony formation, and (E) EdU immunoflurescence assay were carried out to detect the proliferative ability of SW480 and LOVO cell lines treated with siRNA or si-NPR3. (F) Cell apoptosis was performed using flow cytometry. (G) MTT assay and $(\mathrm{H})$ colony formation were performed to determine the proliferative vitality of SW480 cells transfected with vector or pcDNA-NPR3. ${ }^{*} \mathrm{P}<0.05,{ }^{* *} \mathrm{P}<0.01$. All data were presented as the mean \pm S.E.M. from at least 3 independent experiments.

\section{KARGER}




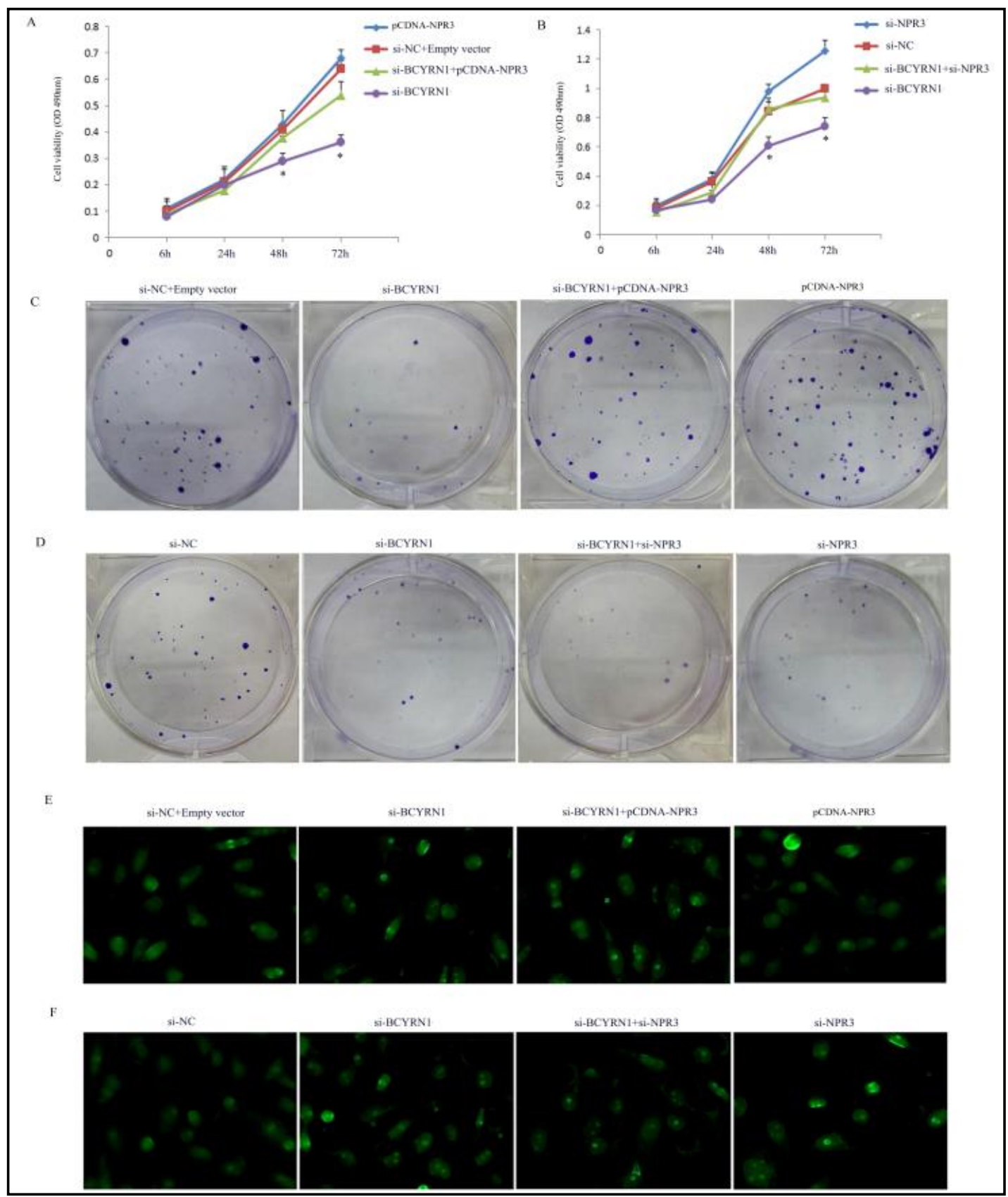

Fig. 6. BCYRN1 promotes CRC cell proliferation through upregulation of NPR3 expression. (A) MTT assay was performed to detect the proliferation of SW480 cells transfected with siBCYRN1 alone or together with pcDNA-NRP3. (B) MTT assay was performed to detect the proliferation of SW480 cells transfected with SiBCYRN1 alone or together with si-NRP3. ${ }^{*} \mathrm{P}<0.05$, ${ }^{* *} \mathrm{P}<0.01$. (C) Colony formation assay was performed to detect the proliferation of SW480 cells transfected with siBCYRN1 alone or together with pcDNA-NRP3. (D) Colony formation assay was performed to detect the proliferation of SW480 cells transfected with siBCYRN1 alone or together with si-NRP3. (C) TUNEL assay was performed to detect the apoptosis of SW480 cells transfected with siBCYRN1 alone or together with pcDNA-NRP3. (D) TUNEL assay was performed to detect the apoptosis of SW480 cells transfected with siBCYRN1 alone or together with si-NRP3. 


\section{Cellular Physiology Cell Physiol Biochem 2018;48:2337-2349 \begin{tabular}{ll|l} 
and Biochemistry Published online: 15 August, 2018 & $\begin{array}{l}\text { (c) } 2018 \text { The Author(s). Published by S. Karger AG, Basel } \\
\text { www.karger.com/cpb }\end{array}$ \\
\hline
\end{tabular}

NPR3 promotes the proliferation and inhibits apoptosis in CRC cells

Next, we determined NRP3 expression in CRC cells and found that NPR3 expression was elevated in SW480, LOVO and GEO cell lines, compared with NCM460 cells (Fig. 5A). MTT assay showed that the proliferation viability was significantly decreased in SW480 and LOVO cell lines after NPR3 knockdown (Fig. 5B-C). Colony formation assay and immunoflurescence assay also showed that knockdown of NPR3 suppressed the proliferation of SW480 and LOVO cells (Fig. 5D-E). Moreover, NPR3 knockdown promoted apoptosis of CRC cells (Fig. 5F). In contrast, overexpression of NPR3 significantly increased cell proliferation in SW480 cells as determined by MTT assay and colony formation assay (Fig. 5G-H). These data suggested that NPR3 could promote the proliferation and inhibit apoptosis in CRC cells.

BCYRN1 promotes the proliferation and inhibits apoptosis of CRC cells via up-regulating NPR3 expression

To investigate the effect of NPR3 on BCYRN1-induced proliferation in CRC cells, cotransfection of si-BCYRN1 and pcDNA-NPR3 was performed subsequently. The results showed that the decreased proliferative ability of BCYRN1 knockdown cells was largely restored following NPR3 overexpression, while NPR3 knockdown further extended the inhibitory effect on clonogenic ability of CRC cells by BCYRN1 knockdown (Fig. 6A-D). Consistently, TUNEL apoptosis assay showed that NPR3 overexpression suppressed the influence of BCYRN1 knockdown on apoptosis (Fig. 6E), while NPR3 knockdown enhanced this effect (Fig. 6F). Together, these results indicated that BCYRN1 promotes CRC cell proliferation via upregulating NPR3.

\section{Discussion}

Recently, increasing evidence has demonstrated that four-fifth of transcription across the human genome is associated with long non-coding RNA sequences [21, 22]. However, the underlying molecular and biological functions correlated with CRC are still unclear [23]. In this study, we found that the expression of IncRNA BCYRN1 significantly upregulated in CRC tissues compared with the adjacent normal controls. Moreover, we found that BCYRN1 expression was associated with tumor size and tumor stage, indicating that BCYRN1 might be a potential prognostic biomarker for CRC. Furthermore, our data showed an increased expression of BCYRN1 in both SW480 and LOVO cell lines compared with NCM460 cells, while a decreased BCYRN1 expression existed in GEO cells. In addition, BCYRN1 knockdown inhibited the proliferative ability and induced apoptosis in SW480 and LOVO cell lines. In contrast, overexpression of BCYRN1 markedly promoted the proliferative vitality of GEO cells. Besides, we also found that BCYRN1knockdown induced G1-phase cell cycle arrest. These results indicated that BCYRN1 contributed to the proliferation and apoptosis of CRC cells.

Recently, it has been reported that abnormal expression of BCYRN1 has an impact on varieties of human cancers $[19,24,25]$. However, the regulatory mechanism of BCYRN1 is still unclear. In this study, we found that BCYRN1 knockdown leaded to downregulation in both transcriptional and translational expressions of NPR3, while overexpression of BCYRN1 had opposite effects.

Our data showed that NPR3 expression was higher in SW480 and LOVO cell lines compared with NCM460 cells. NPR3 knockdown inhibited the proliferation ability, and induced apoptosis in SW480 and LOVO cell lines. In addition, NPR3 overexpression reversed the effects of BCYRN1 knockdown on the proliferative ability and apoptosis in CRC cells. However, the detailed effect and mechanism of BCYRN1 on NPR3 are still needed further investigation. 


\section{Cellular Physiology Cell Physiol Biochem 2018;48:2337-2349 \begin{tabular}{ll|l} 
and Biochemistry Published online: 15 August, 2018 & $\begin{array}{l}\text { (c) } 2018 \text { The Author(s). Published by S. Karger AG, Basel } \\
\text { www.karger.com/cpb }\end{array}$ \\
\hline
\end{tabular} \\ Gu et al.: The Oncogenic Role of BCYRN1 in CRC}

\section{Conclusion}

Our study found that BCYRN1 was up-regulated in CRC tissues. Increased expression of BCYRN1 was closely associated with tumor size and tumor stage. Furthermore, BCYRN1 knockdown inhibited cell proliferation and promoted cell apoptosis. These results indicated that definition of the clinical role of BCYRN1 and its biological functions in CRC may contribute to the discovery of a new diagnostic target and prognostic biomarker for CRC.

\section{Acknowledgements}

This study was supported by the National Natural Science Foundation of China (No. 81272720).

\section{Disclosure Statement}

No conflict of interests exists.

\section{References}

1 Zhang W, Yuan W, Song J, Wang S, Gu X: LncRna CPS1-IT1 Suppresses Cell Proliferation, Invasion and Metastasis in Colorectal Cancer. Cell Physiol Biochem 2017;44:567-580.

-2 Yu B, Ye X, Du Q Zhu B, Zhai Q Li XX: The Long Non-Coding RNA CRNDE Promotes Colorectal Carcinoma Progression by Competitively Binding miR-217 with TCF7L2 and Enhancing the Wnt/beta-Catenin Signaling Pathway. Cell Physiol Biochem 2017;41:2489-2502.

-3 Xu J, Zhang R, Zhao J: The Novel Long Noncoding RNA TUSC7 Inhibits Proliferation by Sponging MiR-211 in Colorectal Cancer. Cell Physiol Biochem 2017;41:635-644.

-4 Cramer H, Lauche R, Klose P, Dobos G, Langhorst J: A systematic review and meta-analysis of exercise interventions for colorectal cancer patients. Eur J Cancer Care (Engl) 2014;23:3-14.

-5 Chen H, Zucknick M, Werner S, Knebel P, Brenner H: Head-to-Head Comparison and Evaluation of 92 Plasma Protein Biomarkers for Early Detection of Colorectal Cancer in a True Screening Setting. Clin Cancer Res 2015;21:3318-3326.

6 Li Y, Li Y, Chen W, He F, Tan Z, Zheng J, Wang W, Zhao Q Li J: NEAT expression is associated with tumor recurrence and unfavorable prognosis in colorectal cancer. Oncotarget 2015;6:27641-27650.

7 Adachi T, Hinoi T, Kinugawa Y, Enomoto T, Maruyama S, Hirose H, Naito M, Tanaka K, Miyake Y, Watanabe M: Lower body mass index predicts worse cancer-specific prognosis in octogenarians with colorectal cancer. J Gastroenterol 2016;51:779-787.

8 Han P, Chang CP: Long non-coding RNA and chromatin remodeling. RNA Biol 2015;12:1094-1098.

$\checkmark 9$ Vitiello M, Tuccoli A, Poliseno L: Long non-coding RNAs in cancer: implications for personalized therapy. Cell Oncol (Dordr) 2015;38:17-28.

10 NE II, Heward JA, Roux B, Tsitsiou E, Fenwick PS, Lenzi L, Goodhead I, Hertz-Fowler C, Heger A, Hall N, Donnelly LE, Sims D, Lindsay MA: Long non-coding RNAs and enhancer RNAs regulate the lipopolysaccharide-induced inflammatory response in human monocytes. Nat Commun 2014;5:3979.

11 Aprea J, Calegari F: Long non-coding RNAs in corticogenesis: deciphering the non-coding code of the brain. EMBO J 2015;34:2865-2884.

12 Marchese FP, Huarte M: Long non-coding RNAs and chromatin modifiers: their place in the epigenetic code. Epigenetics 2014;9:21-26.

13 Hu Y, Chen HY, Yu CY, Xu J, Wang JL, Qian J, Zhang X, Fang JY: A long non-coding RNA signature to improve prognosis prediction of colorectal cancer. Oncotarget 2014;5:2230-2242.

14 Ma Y, Yang Y, Wang F, Moyer MP, Wei Q Zhang P, Yang Z, Liu W, Zhang H, Chen N, Wang H, Wang H, Qin $\mathrm{H}$ : Long non-coding RNA CCAL regulates colorectal cancer progression by activating Wnt/beta-catenin signalling pathway via suppression of activator protein $2 \alpha$. Gut 2016;65:1494-1504. 


\section{Cellular Physiology Cell Physiol Biochem 2018;48:2337-2349

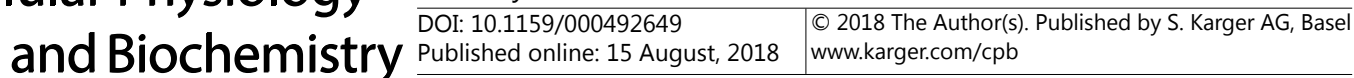 \\ Gu et al.: The Oncogenic Role of BCYRN1 in CRC}

15 Kam Y, Rubinstein A, Naik S, Djavsarov I, Halle D, Ariel I, Gure AO, Stojadinovic A, Pan H, Tsivin V, Nissan A, Yavin E: Detection of a long non-coding RNA (CCAT1) in living cells and human adenocarcinoma of colon tissues using FIT-PNA molecular beacons. Cancer Lett 2014;352:90-96.

16 Kong J, Sun W, Li C, Wan L, Wang S, Wu Y, Xu E, Zhang H, Lai M: Long non-coding RNA LINC01133 inhibits epithelial-mesenchymal transition and metastasis in colorectal cancer by interacting with SRSF6. Cancer Lett 2016;380:476-484.

17 Sun J, Ding C, Yang Z, Liu T, Zhang X, Zhao C, Wang J: The long non-coding RNA TUG1 indicates a poor prognosis for colorectal cancer and promotes metastasis by affecting epithelial-mesenchymal transition. J Transl Med 2016;14:42.

-18 Booy EP, McRae EK, Howard R, Deo SR, Ariyo EO, Dzananovic E, Meier M, Stetefeld J, McKenna SA: RNA Helicase Associated with AU-rich Element (RHAU/DHX36) Interacts with the 3'-Tail of the Long Non-coding RNA BC200 (BCYRN1). J Biol Chem 2016;291:5355-5372.

19 Booy EP, McRae EK, Koul A, Lin F, McKenna SA: The long non-coding RNA BC200 (BCYRN1) is critical for cancer cell survival and proliferation. Mol Cancer 2017;16:109.

20 Yu T, Shan TD, Li JY, Huang CZ, Wang SY, Ouyang H, Lu XJ, Xu JH, Zhong W, Chen QK: Knockdown of lincUFC1 suppresses proliferation and induces apoptosis of colorectal cancer. Cell Death Dis 2016; 7:e2228.

-21 Sanchez Y, Segura V, Marin-Bejar O, Athie A, Marchese FP, Gonzalez J, Bujanda L, Guo S, Matheu A, Huarte M: Genome-wide analysis of the human p53 transcriptional network unveils a IncRNA tumour suppressor signature. Nat Commun 2014;5:5812.

-22 Harrow J, Frankish A, Gonzalez JM, Tapanari E, Diekhans M, Kokocinski F, Aken BL, Barrell D, Zadissa A, Searle S, Barnes I, Bignell A, Boychenko V, Hunt T, Kay M, Mukherjee G, Rajan J, Despacio-Reyes G, Saunders G, Steward C, et al.: GENCODE: the reference human genome annotation for The ENCODE Project. Genome Res 2012;22:1760-1774.

23 Banerjee P, Surendran H, Bharti K, Morishita K, Varshney A, Pal R: Long Noncoding RNA RP11-380D23.2 Drives Distal-Proximal Patterning of the Lung by Regulating PITX2 Expression. Stem Cells 2018;36:218229.

-24 Zhang XY, Tang XY, Ma LJ, Guo YL, Li XS, Zhao LM, Tian CJ, Cheng DJ, Chen ZC, Zhang LX: Schisandrin B down-regulated IncRNA BCYRN1 expression of airway smooth muscle cells by improving miR150 expression to inhibit the proliferation and migration of ASMC in asthmatic rats. Cell Prolif 2017; DOI:10.1111/cpr.12382.

25 Basile V, Vicente A, Martignetti JA, Skryabin BV, Brosius J, Kennedy JL: Assignment of the human BC200 RNA gene (BCYRN1) to chromosome 2p16 by radiation hybrid mapping. Cytogenet Cell Genet 1998;82:271-272. 